$16^{\text {th }}$ International Conference on

AEROSPACE SCIENCES \& AVIATION TECHNOLOGY,

ASAT - 16 - May 26 - 28, 2015, E-Mail: asat@ mtc.edu.eg

Military Technical College, Kobry Elkobbah, Cairo, Egypt

Tel : +(202) 24025292 - 24036138, Fax: +(202) 22621908

\title{
Close-proximity Effects of Metallic nearby Object on a Multi- band Slotted Microstrip Antenna
}

\author{
Ayman Ayd R. Saad ${ }^{*}$, Ahmed A. Ibrahim ${ }^{\dagger}$, Hesham F.A.Hamed ${ }^{*}$ \\ *Kosseir Radio, Telecom Egypt, Kosseir 84712, Egypt, ayman.ramadan@te.eg \\ †Faculty of Engineering, Minia University, Ahmedabdel_monem@mu.edu.eg \\ Faculty of Engineering, Minia University, hfah66@yahoo.com
}

\begin{abstract}
The effect of metallic nearby objects set challenges for multi-band antenna performance due to the behaviour of electromagnetic waves on conductive boundaries. In this paper, the effect of the metallic nearby object on the performance of a multi-band slotted microstrip antenna based on slot loading technique antenna is studied. Two U-shaped slots are inserted into the patch antenna to operate at different frequency band for wireless applications. The proposed antenna has advantages of compactness and multi-functionality. The antenna is designed, fabricated and measured. The performance is evaluated in terms of resonance frequencies, gain and radiation pattern, demonstrating the need to include analysis of multi-band antenna placement early in the design process.
\end{abstract}

Keywords: multi-band; slotted microstrip antenna; housing effect; metallic object

\section{Introduction}

Designing miniature antennas are essential to meet wireless industry requirements for portable and mobile communication devices. In recent years, the miniature multi-band antennas have received much attention for applications of multi-mode communication systems as these antennas are vital for integrating more than one communication standard in a single compact system to effectively promote the portability of a modern personal communication system [1]. To support the high mobility necessity for a wireless communication device, a small and light weight compact microstrip antenna is one of the most suitable printed antennas, even though it usually has a narrow bandwidth [2]. In the last decade, many methods have been reported in order to investigate multi-band operation that suit different applications. The most popular method for obtaining that functionality is incorporating slots in the antenna design either in a radiating patch or a ground plane [3]. This approach is particularly attractive because it can provide excellent bandwidth improvement and maintain a single-layer radiating structure to preserve the antenna's thin profile characteristic. The operating frequency characteristics obtained depend on the shape and position of the slots. Different slots configurations are successfully incorporated into the radiating patch such as, E-shaped [4]-[5], C-shaped [6], Hshaped [7], V-shaped [8], F-shaped [9], S-shape [10], and W-shape [11]. A U-shaped is the most simple and popular slot configuration [12]-[17]. Also metamaterial antenna can be used to achieve multi-functionality [18]-[20].

\footnotetext{
† Faculty of Engineering, Minia University, Ahmedabdel_monem@mu.edu.eg

${ }^{\ddagger}$ Faculty of Engineering, Minia University, hfah66@yahoo.com
} 
The behaviour of a printed antenna depends strongly on the nearby objects of the module where it is integrated [21]. Therefore, in order to integrate the antenna with hosting device, an investigation should be performed to study the antenna housing effect. The main goal of this paper is to find out how the nearby metallic objects affect the performance of the multi-band slotted microstrip antenna. A relatively simple antenna design with slots incorporating in the radiating patch is proposed, to illustrate the impact of an antenna's environment on its performance. In the following Sections, the design procedure is described as well as simulated results and measured data are presented.

\section{Antenna Geometry}

The direction of the fringing field of a microstrip antenna is always from the radiating element to the ground plane, and vice versa [2]. Although this type of an antenna has its own ground plane, its performance will be affected when attached to the metallic object [22]. To make up for this drawback, the slotted microstrip antenna is proposed. The basic structure of proposed antenna is shown in Fig.1. The antenna is printed on $1.575 \mathrm{~mm}$-thick Roger $\mathrm{RT} /$ Duroid $5880\left(\varepsilon_{r}=2.2, \tan \delta=0.0009\right)$ substrate. The antenna is probe fed. The ground plane and the patch dimensions are $50.95 \times 59.00 \mathrm{~mm}^{2}$ and $41.35 \times 49.41 \mathrm{~mm}^{2}$, respectively. To maintain the required multi-band performance, increasing the number of operating frequencies as well as widen its bandwidths, the patch is loaded with double U-shaped slots placed face to face and separated with $2.0 \mathrm{~mm}$, as shown in Fig.1. This slotted configuration is considered because the housing detuning effects are more critical at the patch antenna edges [23]. The form of the U-shaped slot can be considered as a combination of three slots joint together, two vertical slots parallel to $y$-axis and one horizontal slot parallel to the $x$-axis. The gray area is the metal Copper of patch, whereas the white areas inside the gray ones are the slots made by peeling off the metal Copper from dielectric substrate. The horizontal slots have dimensions of $39.35 \times 2.00 \mathrm{~mm}^{2}$. The vertical slots have dimensions of $2.00 \times 15.71 \mathrm{~mm}^{2}$. A strip of width $1.0 \mathrm{~mm}$ is considered between the slots and the left, upper, and right edges of the patch.

The manner the slots are loaded into the patch changes the resonant frequencies due to the disturbance caused to the mean current paths of any resonant frequency (a mode). Changing dimensions and position of a slot causes changes in the effective current paths of a certain mode which in turn forces the resonant frequency of that mode to shift. Since the radiated fields are created by the currents crossing the radiating edges of the patch, then vertical slots placed close to these edges can control the resonance frequency bands.

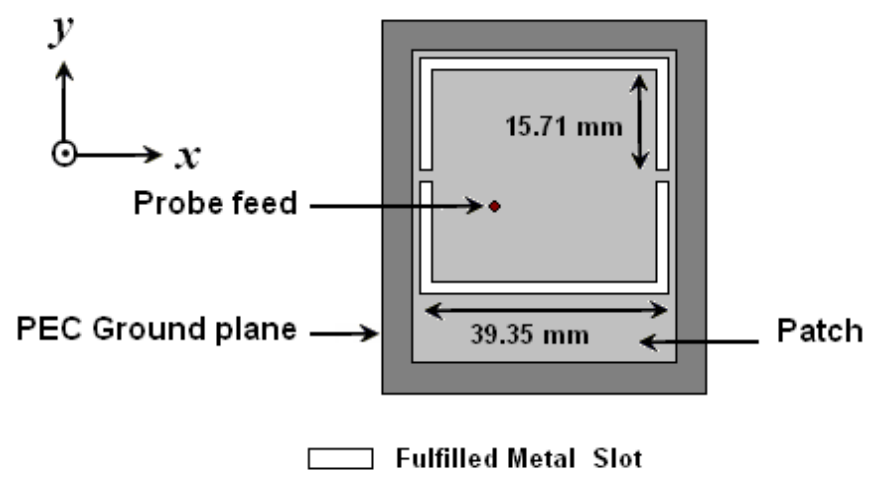

Fig.1. 2-D layout of the proposed antenna with slotted patch. 


\section{Antenna Performance: Results and Discussion}

The simulation of the proposed antenna is performed using the commercial software, IE3D that is based on Method of Moments (MoM) numerical technique. For this simulation the frequency range is set to 2-10 GHz. Several feeding points were tested in order to find the best one of the prototype structure. The center point of the patch is designated as $(0,0)$ and the feeding point is located at $\left(X_{f}, Y_{f}\right)=(-6.75,0)$, which is chosen to give the best matching in the frequency range interest.

The comparison of simulated return loss $\left|S_{11}\right|$ versus frequency of the antenna with and without loading the double U-shaped slots is illustrated in Fig. 2. It is observed that, multiple resonances are obtained from the proposed slots arrangements with reasonable bandwidths, which give the antenna the property of multi-band operation to be used for different applications. Also it can be seen that, using two U-shaped slot increases the numbers of bands than using antenna without slot. As well as, from the simulated results it is obvious that the proposed antenna operates at 2.4, 2.8, 4, 5.8 and $6.8 \mathrm{GHz}$.

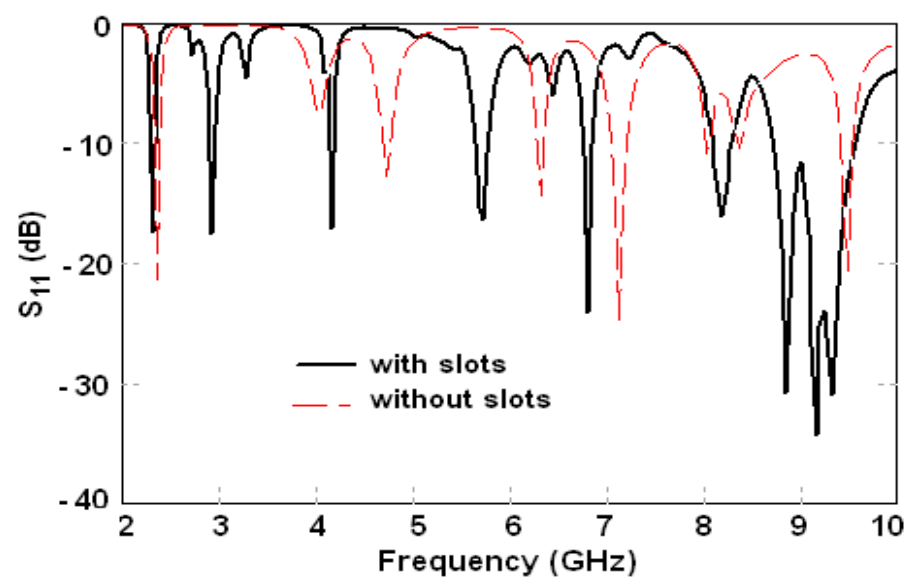

Fig. 2. The simulated return loss $\left|S_{11}\right|$ of the antenna with and without the double $U$ shaped slots.

The parameters that affect the wideband performance of the antenna are the slot length and width, and the position of the slot. When the slot is incorporated to the radiating patch the currents and the excited mode is perturbed which helps to perturbation the effective designed resonant frequency. The higher resonant mode is sensitive to the length variation of the horizontal slots, whereas the lower resonant mode strongly depends on the perimeter vertical slots. These slots act as inductors because they cut off the flow path of the electrical current. For the vertical slot, the electric current travels along a longer path in the patch because the current flows around the slots. This causes the antenna to resonate at the lower frequency band. In contrast, for the horizontal slot, some of the electrical currents can go directly through the slot, thereby shortening the average length of the current path, which enables the antenna to resonate at the higher frequency band. Moreover, the presence of the slot in the vicinity of the feeding probe could add a capacitive load at the input impedance of the patch. This capacitive load could effectively contribute to the resonance of the patch because can counteract the inductive part of the probe's input impedance.

Due to the above mechanism of operation, the resonance frequency and its bandwidth could be controlled by the slots number and the whole configuration of the slots. One of the key advantages of the slot loading technique is add one more degree of freedom for rearranging the slots configuration that might be used to control the resonance frequencies and bandwidths of the antenna, which can be used for different applications. 
To validate the antenna's operation mechanism, the slotted patch antenna was fabricated using photolithographic technique with the same characteristics used in simulation. Fig. 3 shows the photograph of the fabricated antenna. The return loss characteristics $|\mathrm{S} 11|$ of the proposed antenna obtained by simulation and measurement are compared in Fig. 4, in which good agreements are observed. The discrepancy between simulation and measurement could be due to the effect of manufacturing tolerance. Moreover, the coupling between the slots and the presence of the slots in the vicinity of the connector may slightly affect the performance of the antenna.

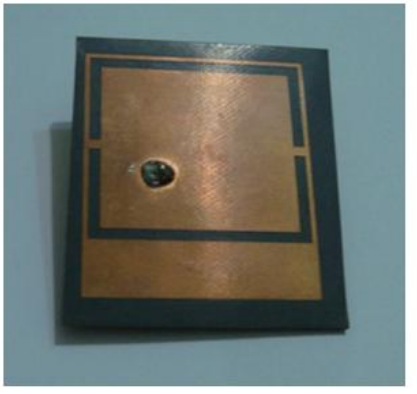

(a)

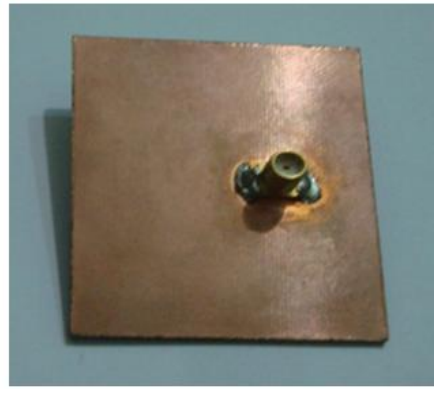

(b)

Fig. 3. Photographs of proposed antenna with the double U-shaped slots. (a) Front view. (b) Back view.

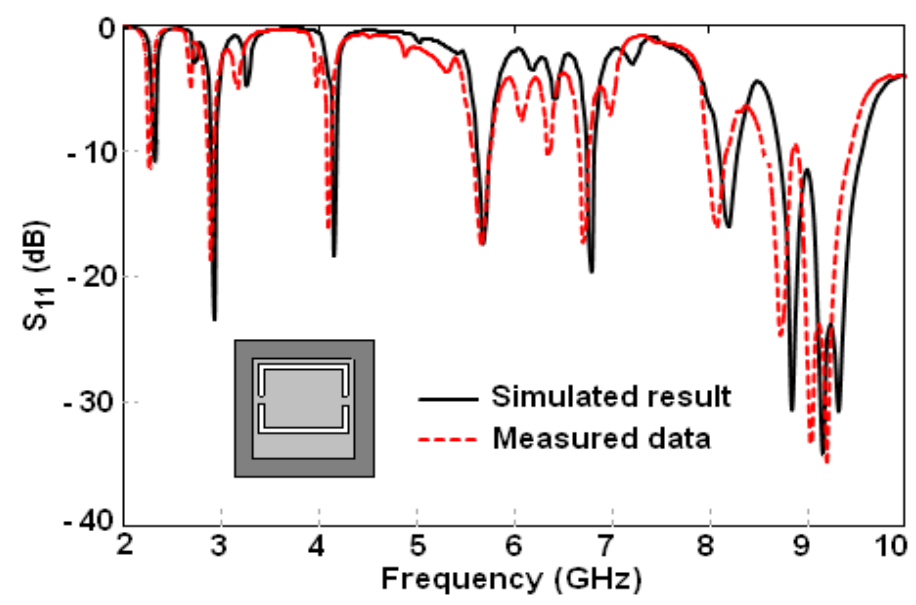

Fig. 4. The measured and simulated return loss $\left|S_{11}\right|$ vs. frequency for the proposed antenna with the double $\mathrm{U}$-shaped slots.

The radiation characteristics and functionality of the proposed antenna are related to the current distribution on its surface. Any slight change in the geometrical configuration of the structure will create new current paths and new radiation edges, which give the antenna new resonances and different operation. Fig. 5 illustrates the simulated peak gain and radiation efficiency of the proposed antenna over the frequency band of interest. 


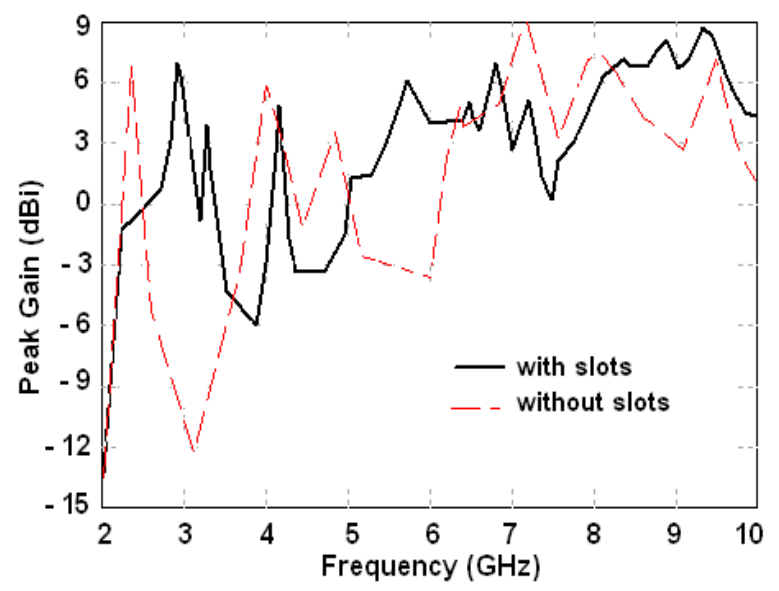

(a)

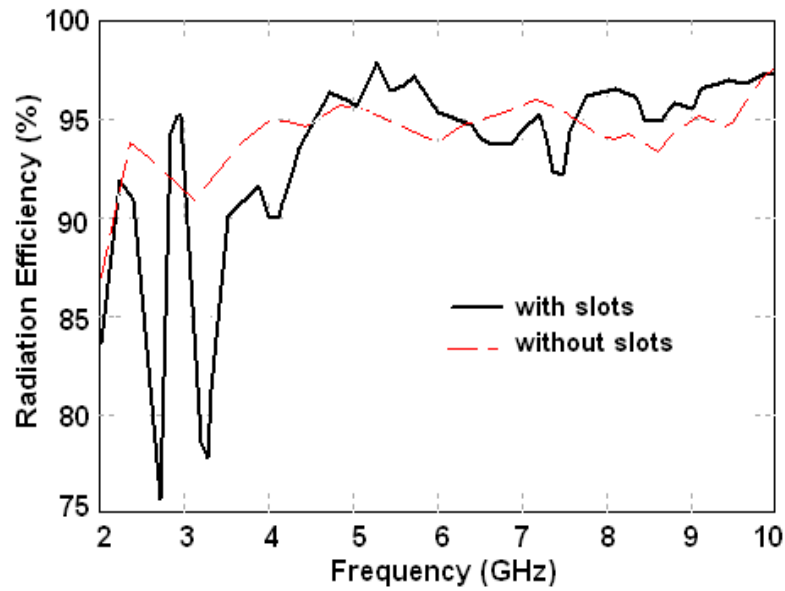

(b)

Fig. 5: The simulated (a) peak gain (b) radiation efficiency.

\section{Effects of Metallic Surface on Antenna Performance}

In mobile and vehicular applications, the antenna could be used in proximity to a variety of materials, such as metal objects or the human body. Metallic surface or object in the vicinity of an antenna changes its radiation pattern, input impedance, radiation efficiency and resonant frequency. These changes depend on the size and shape of the metallic object and also on the distance of the antenna from the object [24]-[25]. When the antenna radiates in the vicinity of an object, the backscattered fields produced by the object induce electric current on the antenna, affecting the antenna performance. Therefore, the housing effect of such nearby devices on the antenna performance is a critical factor [26]-[27].

The orientation of the antenna to a nearby object is critical in maintaining the performance of the antenna [28]. The worst case scenario of housing effect setup is when the antenna is located in the front of the metallic surface, as shown in Fig. 6. The front of the antenna is placed closely above the metallic surface keeping air as the medium between them.

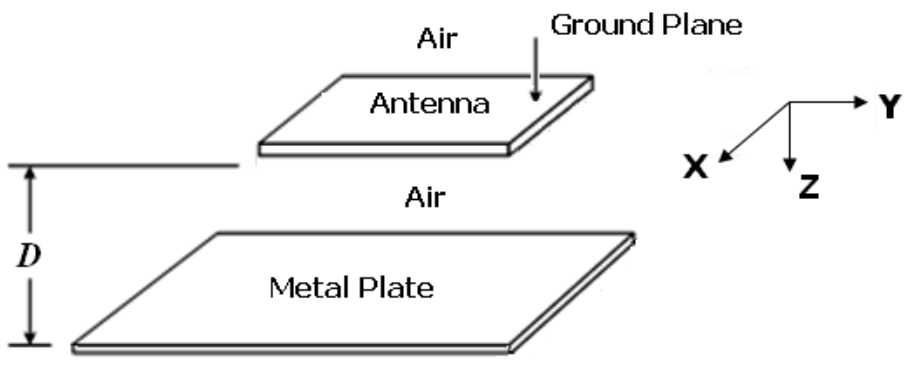

Fig. 6.The isometric view of the housing effect setup to investigate the performance of the antenna in the vicinity of metallic surface.

After optimized the proposed antenna structure, the effects on antenna parameters when placed horizontally near a metal plate, as shown in Fig. 6, are investigated. The antenna configurations with and without loading the double U-shaped slots, are studied. For each configuration a simulation is done and the results are compared to the free space results. Analysis on resonant frequencies, gain and radiation pattern of the proposed antenna is investigated for different separation distances. A $100 \mathrm{~mm} \times 100 \mathrm{~mm}(0.8 \lambda \times 0.8 \lambda$ at $2.4 \mathrm{GHz})$ Copper sheet placed closely in the front of the antenna with a separation distance of $\mathrm{D}=2,5$ and $9 \mathrm{~mm}(\mathrm{D}=0.016 \lambda, 0.04 \lambda$ and $0.072 \lambda$ at $2.4 \mathrm{GHz}$, respectively) is considered. At every distance, the performance of proposed antenna is examined. 
Fig. 7 presents the investigation and analysis of the effects of a metallic surface on the resonance frequencies of the proposed antenna for different separation distances as considered. The performance is evaluated in terms of return loss, bandwidth and shift in resonance frequencies. Fig. 7(a) shows the return loss $\mid$ S11 $\mid$ characteristics versus frequency of the proposed antenna without loading the U-shaped slots. It can be observed that, for all the separation distances, the metallic surface affecting the impedance matching of the antenna and degrading its performance over the frequency band of interest. The results in Fig. 7(b) are for the antenna when incorporated with the double U-shaped slots. It can be seen that the antenna performance is affected less, due to the variation in the inductance caused by the slots. Shift in antenna resonant frequencies is occur at $\mathrm{D}=0.072 \lambda$ and $0.04 \lambda$, especially in high frequency band. Severe degradation in the resonance frequency is observed for the antenna mounted near a metal plate by $\mathrm{D}=0.016 \lambda$, although the antenna still operates at 2 and $6 \mathrm{GHz}$ frequency bands. Since the metal plate is so close to the antenna it's radiating element acts like a microstrip line and radiation is suppressed [29].

From the obtained results, it can be inferred that, the slots weakened the effects of the metallic surface. The placement distance of the antenna is the most significant parameter. Furthermore, simulation study not shown here (for brevity) showed that, for the two antenna configurations, as the separation distance, $\mathrm{D}$ increases than $0.072 \lambda$ the degradation in antenna performance decreases. At $\mathrm{D}<0.016 \lambda$ the antenna performance over the whole frequency band is significantly deteriorates which is due to the adverse effect of the antenna image [28]. On the other hand, the shift in resonant frequency due to increase the size of metal plate is very low. Also, the study showed that the thickness of the metal plate has almost no effect on antenna performance.

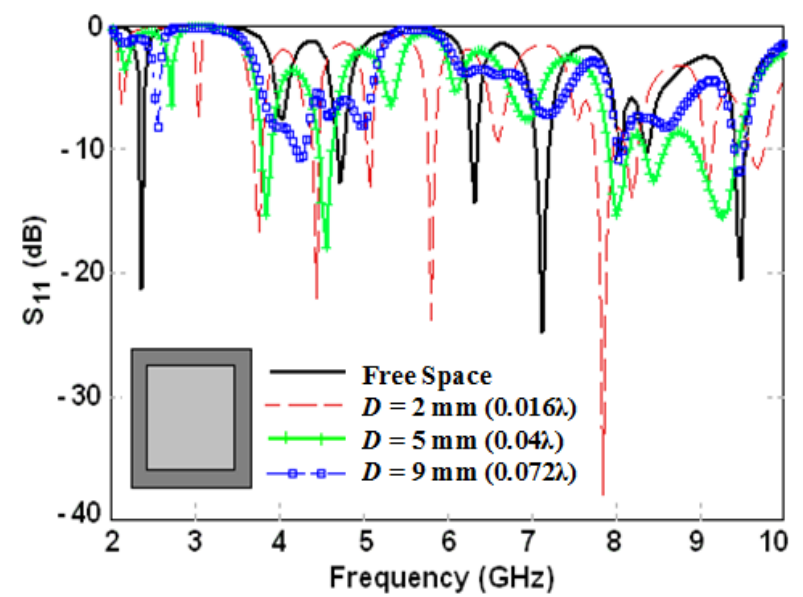

(a)

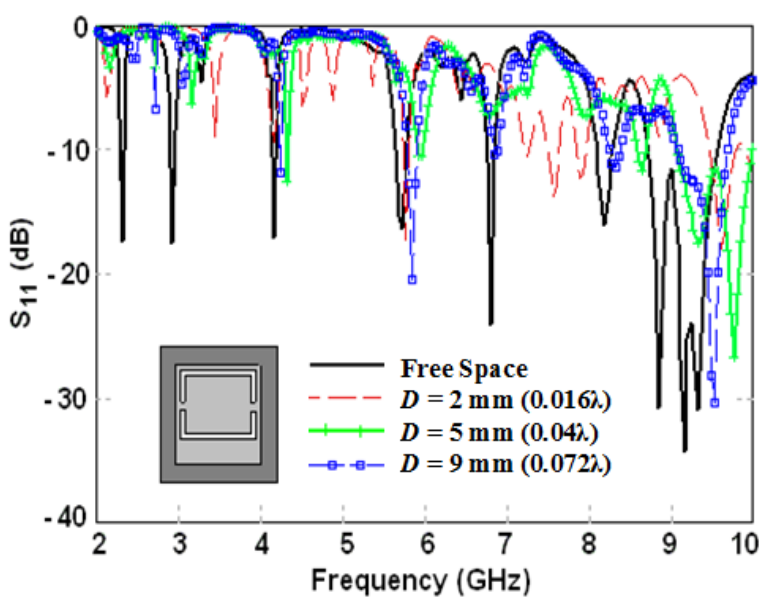

(b)

Fig. 7. Impact of metal plate on return loss $\left|S_{11}\right|$ characteristics of the proposed antenna for various separation distances, $D$. (a) Without loading slots. (b) With loading the double U-shaped slots.

Fig. 8 demonstrates the impact on peak gain variation when a metal plate is placed nearby the proposed antenna with and without loading slots, for the same separation distances, $\mathrm{D}=$ $0.016 \lambda, 0.04 \lambda$ and $0.072 \lambda$ at $2.4 \mathrm{GHz}$. An interesting point to note is the fact that the peak gain is greater when the metal plate is included in the analysis, even when $\mathrm{D}=0.016 \lambda$, the nearest separation in the study, the peak gain is enhanced by reducing backward radiations. When the antenna is attached to metallic objects it develops interference as metal is an electromagnetic reflector and radio signals cannot penetrate through it. This leads to a conclusion that sometimes the metal plate is also part of the antenna even though the plate is not physically connected to the antenna [29]. Therefore, careful attention needs to be placed on analyzing the antenna's performance when objects are close to the antenna. 
Far-field radiation patterns of the proposed antenna with double U-shaped slots, in free space and by the presence of the metal plate were also simulated for various separation distances, and shown in Fig. 9. Obvious metal plate affects the radiation pattern characteristics. It is clear that the metal plate directs the energy in perpendicular direction. The back radiation in the $-\mathrm{z}$ direction is decreased when the antenna is mounted on the metal plate. There are some nulls also observed due to the diffraction effect of the metallic surface. The number of nulls increases as frequency increases.

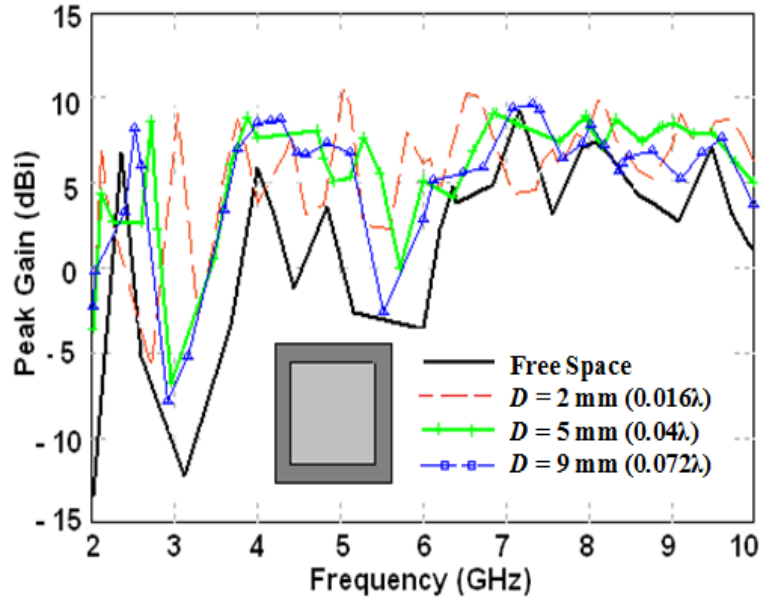

(a)

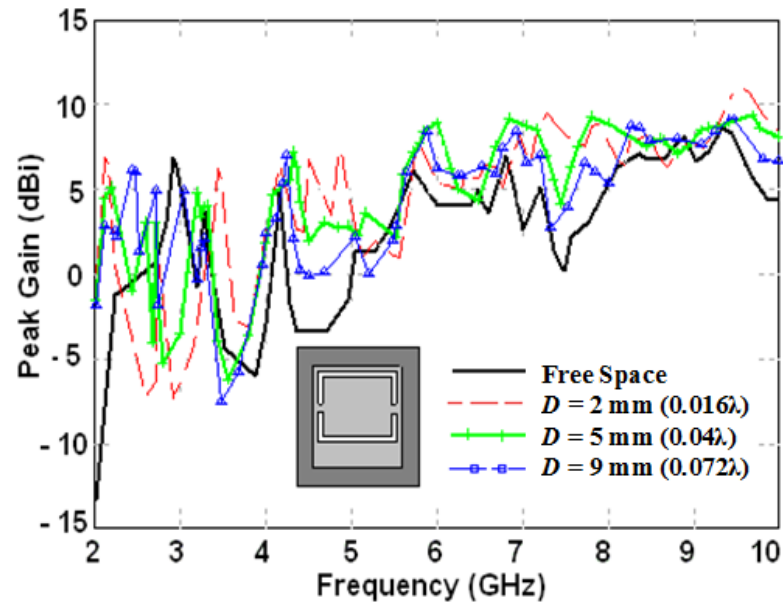

(b)

Fig. 8. Impact of metal plate on peak gain of the proposed antenna for various separation distances, $D$. (a) Without loading slots. (b) With loading the double U-shaped slots.

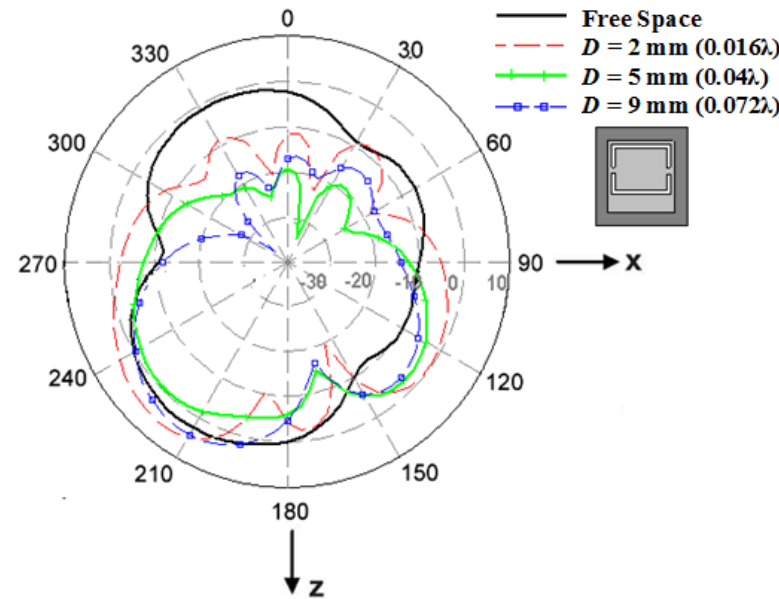

(a)

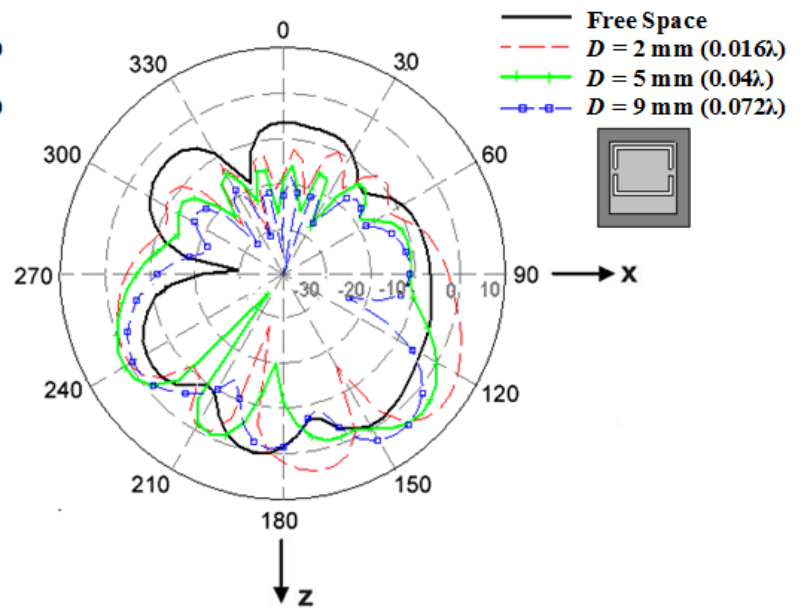

(b)

Fig. 9. Simulated far-field radiation pattern of $E_{\theta}$ in the $x z$-plane in free space and on $(0.8 \lambda \times 0.8 \lambda$ at $2.4 \mathrm{GHz})$ metal plate for the proposed antenna with loading the double $\mathrm{U}$ shaped slots at, (a) $5.5 \mathrm{GHz}$. (b) $10 \mathrm{GHz}$.

\section{Conclusion}

Designing multi-band antenna nearby metallic object is a challenging task as antenna parameters are highly affected by metallic surface. In this analysis, it is observed that, the metallic object near the multi-band microstrip antenna has both positive and negative effects on the performance of the antenna. The positive effect is increasing the antenna gain and 
improving the radiation pattern by reducing the back lobes when the antenna is placed in the vicinity of a metal plate. On the other hand, the negative effect is represented in degradation of the resonant frequencies and bandwidths. All these effects depending on the separation distance between the antenna and the metallic surface. A solution to alleviate the effects is to re-tune or co-design the antenna in close-proximity with the metallic object based on the information from this study.

\section{References}

[1] Aabidi ES, Kamarudin MR, Rahman TA, Iddi HU. Multi-band circular patch antenna for wideband application. PIERS Proceedings; Aug. 2013; Stockholm; Sweden; p. 130-133.

[2] Pozar DM, Schaubert DS. Microstrip Antennas: The analysis and design of microstrip antennas and arrays, John Wiley \& Sons, Inc.; Hoboken; New Jersey; May 1995.

[3] Siakavara K. Methods to design microstrip antennas for modern applications, microstrip antennas, Nasimuddin N (Ed.); InTech; Rijeka, Croatia; 2011.

[4] Yang F, Zhang X-X, Ye X, Rahmat-Samii Y. Wide-band E-shaped patch antennas for wireless communications. IEEE Trans. Antennas Propag. 2001;49:1091-1100.

[5] Ang BK, Chung BK. A wideband E-shaped microstrip patch antenna for $0-6 \mathrm{GHz}$ wireless communications. Prog. Electromagn. Res. 2007;75:397-407.

[6] Sanad M. Double C-patch antennas having different aperture shaped. In Proc. IEEE APS Symp Digest; Newport Beach; CA; June 1995; Vol. 4; p. 2116-2119.

[7] Sheta A, Mohra A, Mahmoud SF. Multi-band operation of a compact H-shaped microstrip antenna. Microwave Opt Technol Lett. 2002;35:363-367.

[8] Rafi G, Shafai L. Broadband microstrip patch antenna with V-slot. IEE Proc. Microw. Antenna Propag. 2004;151:435-440.

[9] Lai J, Kan JHK, Rowe WST. Dual frequency F-shaped shorted patch antenna. Microwave Opt Technol Lett 2006;48:1811-1812.

[10] Zulkifli FY, Narpati F, Rahardjo ET. S-shaped patch antenna fed by dual offset electromagnetically coupled for 5-6 GHz high speed network. PIERS ONLINE. 2007;3:163-166.

[11] Ansari JA, Mishra A, Yadav NP, Singh P, Vishvakarma BR. Analysis of W-slot loaded patch antenna for dualband operation. Int. J. Electron. Commun. (AEÜ). 2012;66:3238.

[12] Huynh T, Lee KF. Single-layer single-patch wideband microstrip antenna. Electron. Lett. 1995;31:1310-1312.

[13] Lee KF, Luk KM, Tong KF, Shum SM, Huynh T, Lee RQ, Experimental and simulation studies of the coaxially fed U-slots rectangular patch antenna. IEE Proc. Microw. Antenna Propag. 1997;144:354-358.

[14] Yang, S-L S, Kishk AA, Lee K-F. Frequency reconfigurable U-slot microstrip patch antenna. IEEE Antennas Wireless Propag. Lett. 2008;7:127-129.

[15] Lu J-H, Chou W-C. Planar dual U-shaped monopole antenna with multiband operation for IEEE 802.16e. IEEE Antennas Wireless Propagat. Lett. 2009;9:1006-1009.

[16] Lee KF, Luk KM, Mak KM, Yang SL. On the use of U-slots in the design of dual-and triple-band patch antennas. IEEE Antennas Propaga. Magazine. 2011;53:60-73.

[17] Murugan S, Kumar ES, Rajamani V. Design and analysis of double U slot loaded dual frequency microstrip antenna. Prog. Electromagn. Res. C. 2013;45:101-112.

[18] Mahmoud Abdalla, Mohamed Fouad, Aser Ahmed, and Zhirun Hu, "A New Compact Microstrip Triple Band Antenna Using Half Mode CRLH Transmission Line" 2013 IEEE AP-S International Antenna and Propagation Symposium Digest, Jul. 7-13, 2013, Orlando, USA, pp. 634-635.

[19] Mahmoud Abdalla, Mohamed Abo El-Dahab, Mohamed Ghouz, "Dual/Triple Band Printed Dipole Antenna Loaded With CRLH Cells", 2014 IEEE AP-S International 
Antenna and Propagation Symposium Digest, Jul. 6-11, 2014, Memphis, USA, pp. 1007-1008.

[20] M. A. Abdalla, U. Abdelnaby and A. A. Mitkees ," Compact and triple and metamaterial antenna for all WiMAX applications", 2012 International Symposium on Antennas and Propagation (ISAP), Oct. 29 2012-Nov. 2 2012, pp. 1176 - 1179

[21] Bahadori K, Rahmat-Samii Y. A miniaturized elliptic-card UWB antenna with WLAN band rejection for wireless communications. IEEE Trans. Antennas and Propagat. 2007;55:3326-33332.

[22] Islam Md, Yussuf A, Zahirul AHM, Ismail AF, Chebil J, Khan S. Design of a passive RFID tag antenna at $2.45 \mathrm{GHz}$ for mounting on various platforms. In proc. IEEE Inter. RF and Microwave Conf.; Dec. 2011; Seremban; Malaysia; p. 344-348.

[23] PCTEL, Inc., Using the 1357D embedded $13 \mathrm{~mm}$ GPS antenna, Application Note.

[24] Raumonen P, Sydanheimo L, Ukkonen L, Keskilammi M, Kivikoski M. Folded dipole antenna near metal plate. In Proc. IEEE AP-S Int. Symp.; Jun. 2003; Columbus; OH; Vol. 1, p. 848-851.

[25] Sydänheimo L, Ukkonen L, Kivikoski M. Effects of size and shape of metallic objects on performance of passive radio frequency identification. Int J Adv Manuf Technol. 2006;30:897-905.

[26] Lin C-C, Kuo S-W, Chuang H-R. A 2.4-GHz printed meander-line antenna for USB WLAN with notebook-PC housing. IEEE Microw. Wireless Components Lett. 2005;15:546-548.

[27] Mehdipour A, Sebak A-R, Trueman CW. Compact microstrip-fed antenna for 2.4/5.2/5.8 GHz wireless communication systems. In Proc. IEEE AP-S Int. Symp.; Jun. 2009; Charleston; SC; p. 1-4.

[28] Mehdipour A, Sebak A-R, Trueman CW, Denidni TA. Compact multiband planar antenna for $2.4 / 3.5 / 5.2 / 5.8 \mathrm{GHz}$ wireless applications. IEEE Antennas Wireless Propag. Lett. 2012;11:144-147.

[29] DeJean GR, Mercer S. Antenna environment impacts efficiency and radiation pattern. High Frequency Electronics. Aug. 2009;18-27. 